\title{
Magneto-sensitive hybrid nanocomposites of water-soluble sodium alginate cross-linked with calcium ions and maghemite
}

\author{
V. V. Spiridonov ${ }^{1}$, I. G. Panova ${ }^{1}$, L. A. Makarova ${ }^{2}$, S. B. Zezin ${ }^{1}$, A. A. Novakova ${ }^{2}$, T. G. Baluyan ${ }^{2}$, \\ A. V. Sybachin ${ }^{*}$, V. V. Kuznetsov ${ }^{1}$, A. A. Yaroslavov ${ }^{1}$
}

${ }^{1}$ Department of Chemistry, Lomonosov Moscow State University, Leninskie gory, 1-3, 119991 Moscow, Russia

${ }^{2}$ Department of Physics, Lomonosov Moscow State University, Leninskie gory, 1-2, 119234 Moscow, Russia

Received 18 October 2017; accepted in revised form 29 December 2017

\begin{abstract}
A synthetic procedure is described for preparation of magneto-sensitive nanocomposites from maghemite nanoparticles and a natural polysaccharide, sodium alginate cross-linked with calcium ions. With this procedure, a series of nanocomposites was synthesized and characterized by spectrophotometry, transmission electron microscopy, X-ray diffraction, Mössbauer spectroscopy, Fourier transform IR-spectroscopy and magnetometry with the following main conclusions: (a) The nanocomposites retain their solubility in water unless the iron content exceeds $18.1 \pm 0.2 \mathrm{wt} \%$. (b) Only $\gamma-\mathrm{Fe}_{2} \mathrm{O}_{3}$ nanoparticles

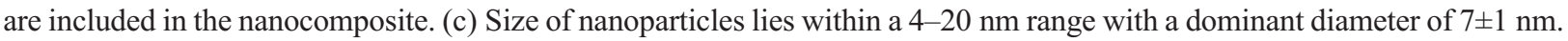
(d) Maghemite nanoparticles bind to the alginate matrix via formation of electrostatic and coordination contacts between the surface $\mathrm{Fe}^{3+}$ maghemite ions and functional alginate groups. (e) The nanocomposites exhibit properties which are characteristic for soft magnetic materials since they have a low coercive force. (f) Magnetic characteristics of the nanocomposites, saturation magnetization and residual magnetization, are effectively controlled by the maghemite content. (g) An external magnetic field causes the nanocomposites to move in an aqueous dispersion.
\end{abstract}

Keywords: polymer composites, nanocomposites, biodegradable polymers, magnetic, nanoparticles

\section{Introduction}

Search for new synthetic approaches to make magnetically controlled hydrophilic nanocomposites is of great interest because of their active application in medicine and biotechnology. Such composites are sensitive to an external magnetic field that allows their transport in the body $[1,2]$, in particular for a targeted delivery of drugs and radionuclides to a specific area of the organism [3, 4]. Importantly, the magnetic field does not have a destructive effect on living tissue. This feature makes the magnetic field an effective tool for therapeutic hyperthermia of tumor cells $[5,6]$, and often as an addition to traditional therapies [7-9]. The most widespread in medical practice are composite materials based on iron oxides, magnetite and maghemite, which demonstrate an acceptable toxicity together with satisfactory magnetic properties $[10,11]$. Magnetite $\mathrm{FeO}-\mathrm{Fe}_{2} \mathrm{O}_{3}$ is oxidized in the presence of oxygen $[12,13]$ that results in water-soluble but non-magnetic products [14, 15]. In contrast to this, maghemite $\mathrm{Fe}_{2} \mathrm{O}_{3}$ is chemically stable in physiological solution. For this reason, maghemite-based nanocomposites seem more prospective [16]. Iron oxide nanoparticles are usually incorporated into biocompatible matrix, e.g. small organic compounds, polymers, interpolymer capsules [17-19], in order to reduce toxicity of nanoparticles and stabilize them against spontaneous aggregation. In addition, conjugation of nanoparticles with hydrophilic polymers increases the time of their circulation in the bloodstream $[20,21]$. As effective stabilizers have been suggested polymers with ionic 
groups, synthetic and natural polyelectrolytes, including chitosan, alginic acid and carboxymethyl cellulose [22-24]. The presence of charged functional groups in this case allows polymers to chemically interact with the surface of nanoparticles.

Alginate is a commercially available anionic polysaccharide extracted from seaweeds [25] with an annual production of approx. 30000 tons [26, 28], which has been long used in pharmacy and cosmetics [27, 28]. Alginate itself possesses various kinds of physiological activities, such as anti-tumor $[29,30]$ and immune-regulating $[31,32]$ activity. In $\mathrm{Ca}^{2+}$-containing aqueous solutions, this polymer forms microgel particles recommended for encapsulation and transport of bioactive compounds [33, 34]. Being electrostatically combined with cationic polysaccharide chitosan, anionic alginate gives micro-sized capsules, another drug-delivery device [35]. Conjugation of alginate with iron oxide nanoparticles allows obtaining magnetically controlled biocompatible and biodegradable nanocomposites for encapsulation and delivery of various biologically active compounds.

A basic procedure for the preparation of water soluble nanocomposites from iron oxide nanoparticles and sodium alginate is a co-precipitation in situ technique [36]. Ma and coworkers [37, 38] proposed a two-step method that involved the synthesis of magnetite from a mixture solution of $\mathrm{Fe}$ (II) and $\mathrm{Fe}(\mathrm{III})$ salts in alkaline solution and then the combination of the particles obtained with alginate by dispersion using ultrasonication. The authors of refs. [39-41] prepared superparamagnetic sodium alginate-coated $\mathrm{Fe}_{3} \mathrm{O}_{4}$ nanoparticles as a magnetic adsorbent in which $\mathrm{Fe}_{3} \mathrm{O}_{4}$ nanoparticles were synthesized from $\mathrm{FeCl}_{3}$ and $\mathrm{FeCl}_{2}$ under alkaline medium in the presence of sodium alginate. The processes of obtaining nanocomposites are carried out both at $60-80^{\circ} \mathrm{C}$ and in inert (nitrogen or argon) atmosphere [37-41], and in air atmosphere [42]. It was shown that nanocomposites iron oxide nanoparticles/sodium alginate are characterized by stability against aggregation and well-defined magnetic properties. However, all proposed modifications of the co-precipitation method give a $\mathrm{FeO}-\mathrm{Fe}_{2} \mathrm{O}_{3}$ mixture (magnetite).

In the present article we first time describe water soluble and magnetically controlled nanocomposite materials weakly cross-linked salt of alginic acid (sodium/calcium alginate) and maghemite nanoparticles. Nanocomposites were obtained by one-step synthesis of $\gamma-\mathrm{Fe}_{2} \mathrm{O}_{3}$ from Mohr's salt in a polymeric alginate matrix. The proposed technique of chemical synthesis of maghemite develops in alkaline solution at room temperature and air atmosphere. The content of magnetic component in the composites can be controlled by the ratio of the components in the synthesis.

\section{Experimental section}

\subsection{Materials}

Mohr's salt $\left(\mathrm{NH}_{4}\right)_{2} \mathrm{Fe}\left(\mathrm{SO}_{4}\right)_{2} \cdot 5 \mathrm{H}_{2} \mathrm{O}$ (Merck, USA), $\mathrm{NaH}_{2} \mathrm{PO}_{2}$ (VK Labor und Feinchemikalien, Germany), $\mathrm{NaOH}$ (Chemapol, Czech Republic), and 2hydroxy-5-sulphobenzoic acid (Sigma-Aldrich, USA) were used as received. Na-alginate cross-linked with calcium ions (5\%) (Alg- $\mathrm{Na} / \mathrm{Ca})$ from (ISP, Waterfield, Tadworth Surrey, United Kingdom) was purified by dialysis against bi-distilled water for three days. To extract polymer substance the solution was exposed to lyophilic drying.

\subsection{Nanocomposites synthesis}

The four nanocomposites were synthesized as follows. Weighted amounts of Mohr's salt were dissolved in $1 \mathrm{~mL}$ of distilled water each and mixed with corresponding $5 \mathrm{~mL}$ of $2 \%$ aqueous solution of $\mathrm{Alg}-\mathrm{Na} / \mathrm{Ca}$ and $1 \mathrm{~mL}$ of $2 \mathrm{mM} \mathrm{NaOH}$ aqueous solution. The resulting three-component systems were intermixed vigorously for $2 \mathrm{~min}$ and then each system was added to $1 \mathrm{~mL}$ of $\mathrm{NaH}_{2} \mathrm{PO}_{2}$ solution whose concentration ensured a molar ratio $\left(\mathrm{NH}_{4}\right)_{2} \mathrm{Fe}\left(\mathrm{SO}_{4}\right)_{2} \cdot 5 \mathrm{H}_{2} \mathrm{O} / \mathrm{NaH}_{2} \mathrm{PO}_{2}=1 / 1$. The reactions were completed when a color of the mixtures changed from green to dark red. The resulting solutions were purified from inorganic salts by dialysis, after that $\mathrm{Fe} / \mathrm{Alg}-\mathrm{Na} / \mathrm{Ca}$ nanocomposites were lyophilized. Thus the nanocomposites I-IV were obtained. The details about initial components composition in the reaction mixture are presented in Table 1 . The procedure proposed enabled us to obtain relatively large quantities (tens of milligrams) of magnetic nanocomposites with the average yield $80 \pm 5 \%$.

\subsection{Instrumentation}

The iron contents in the nanocomposites ( $\beta$ in Table 1) were determined spectrophotometrically by Ultrospec 4050 (LKB, Sweden). For this purpose $5 \mathrm{mg}$ samples of each lyophilized nanocomposite were dissolved in $0.1 \mathrm{~mL}$ of $10 \mathrm{mM} \mathrm{H}_{2} \mathrm{SO}_{4}$ aqueous solution and mixed with $5 \mathrm{~mL}$ of $10 \%$ 2-hydroxy-5-sulphobenzoic acid aqueous solution. Absorbance at $510 \mathrm{~nm}$ was registered, recalculated in a Fe concentration 
using a corresponding calibration curve and finally transformed to a $\beta$ value. Maximum iron contents in water-soluble composites were calculated taking into account the confidence interval of $95 \%$. The confidence intervals of mean values were calculated using program Excel.

Morphological studies were carried out using transmission electron microscopy (TEM) with a JEM100B unit (JEML, Japan) equipped with an attachment for X-ray phase analysis. Diluted $0.005 \mathrm{wt} \%$ water solutions of composites were prepared. The $5 \mu \mathrm{L}$ aliquots of these solutions were set to copper grids and dried in vacuo. Samples were examined without preliminary contrasting. Nanoparticles sizes were established by means of statistical analysis of TEM images using MicroCal Origin software. The analysis of 30 samples for each specimen was performed. $\mathrm{X}$-ray diffraction (XRD) measurements were carried out in a transmission mode using URD-6 diffractometer (Carl Zeiss, Germany). The particles sizes were calculated by the Debye-Scherrer formula.

Mössbauer spectra of the nanocomposites were obtained with a MS-1104EM spectrometer (Russia, Rostov University) with the ${ }^{57} \mathrm{Co}(\mathrm{Rh})$ gamma-radiation in source in transmission geometry at 300 and $80 \mathrm{~K}$. A model interpretation of the Mössbauer spectra was performed using Univem MS Program.

Magnetic properties of the nanocomposites were studied with a Lakeshore 7400 vibration magnetometer (Lake Shore Cryotronics, USA) at room temperature in a field range of \pm 6 Oe. A previously compacted sample was oriented in parallel to an external magnetic field.

Fourier transform IR-spectra (FTIR) were recorded using by PerkinElmer Spectrum 100 FT-IR technique in the range of $4000-400 \mathrm{~cm}^{-1}$ at room temperature.

\section{Results and discussion}

The (iron-containing) Fe/alginate nanocomposites were synthesized via one-stage transformation of Mohr's salt, $\left(\mathrm{NH}_{4}\right)_{2} \mathrm{Fe}\left(\mathrm{SO}_{4}\right)_{2} \cdot 6 \mathrm{H}_{2} \mathrm{O}$, to $\mathrm{Fe}_{2} \mathrm{O}_{3}$ in alkaline solution additionally contained a strong reducing agent, sodium hypophosphite, and a stabilizing polymer matrix, alginate crosslinked with calcium ions. No special conditions (high temperature and inert medium) were required. Recently [43] we established that the feature of the proposed method is the formation of magnetic $\mathrm{Fe}_{2} \mathrm{O}_{3}$ oxide in the presence of a strong reducing agent and air oxygen. The presence of a reducing agent in the system was necessary due to the chemical specificity of this process, which proceeds through the formation of metallic iron as an intermediate. It should be noted that magnetic iron oxide form could not be synthesized without the reducing agent. The choice of hypophosphite as a reducing agent was made because oxidation-reduction potential of the $\mathrm{H}_{2} \mathrm{PO}_{2}^{-} / \mathrm{PO}_{4}^{3-}$ pair provides recovery to metallic iron in an alkaline medium.

In the course of synthesis, the alginate concentration was maintained constant, whereas the Mohr salt concentration increased that allowed to see how a Mohr's salt-to-alginate molar ratio $N$ affected the iron content in the nanocomposite $\beta$. As shown in Table 1, the iron content progressively increased with elevating $N$ and reached 18.1 at $N=2$. In all samples water-soluble products were formed, while an increase in the Mohr salt concentration over $0.12 \mathrm{M}$ resulted in black precipitates. The formation of nuclei, nanocrystals of iron-containing particle as well as formation of contacts between the surface of nanoparticles and macromolecules occurs during the synthesis of nanoparticles. Alginate macromolecules play a key role providing limited volume for nucleation and growth of nanoparticles. So this steric factor plays dominant role in limiting the growth of nanocrystals.

The results were reproduced when repeating the synthetic procedure. Thus, the content of the inorganic phase in the polymer matrix could be controlled by simple varying a ratio of two components: Mohr's salt and alginate.

The iron-containing nanoparticles in the nanocomposites were visualized by using the TEM technique.

Table 1. Content of initial components in the reaction mixture and iron content in the composites.

\begin{tabular}{|c|c|c|c|c|}
\hline Composite & $\begin{array}{c}{[\mathrm{Alg}-\mathrm{Na} / \mathrm{Ca}]} \\
{[\mathrm{M}]}\end{array}$ & $\begin{array}{c}{\left[\left(\mathrm{NH}_{4}\right)_{2} \mathrm{Fe}\left(\mathrm{SO}_{4}\right)_{2} \cdot 5 \mathrm{H}_{2} \mathrm{O}\right]} \\
{[\mathrm{M}]}\end{array}$ & {$\left[\left(\mathrm{NH}_{4}\right)_{2} \mathrm{Fe}\left(\mathrm{SO}_{4}\right)_{2} \cdot 5 \mathrm{H}_{2} \mathrm{O}\right] /[\mathrm{Alg}-\mathrm{Na} / \mathrm{Ca}]=N$} & $\begin{array}{c}\beta \\
{[w t \%]}\end{array}$ \\
\hline $\mathrm{I}$ & 0.06 & 0.015 & 0.25 & $3.4 \pm 0.1$ \\
\hline II & 0.06 & 0.030 & 0.50 & $4.8 \pm 0.1$ \\
\hline III & 0.06 & 0.060 & 1.00 & $10.5 \pm 0.2$ \\
\hline IV & 0.06 & 0.120 & 2.00 & $18.1 \pm 0.2$ \\
\hline
\end{tabular}




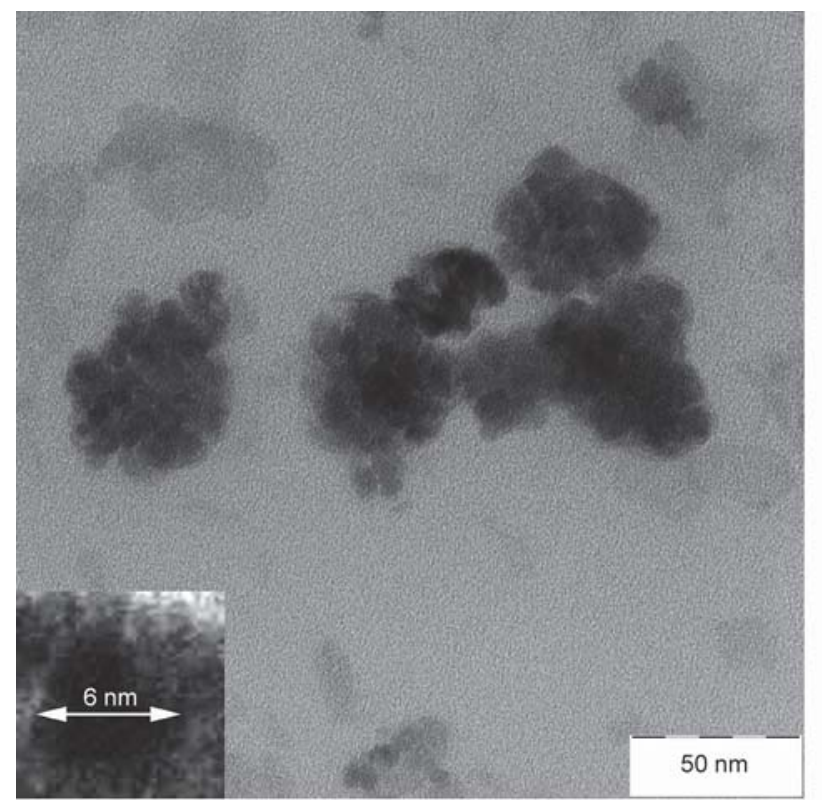

a)

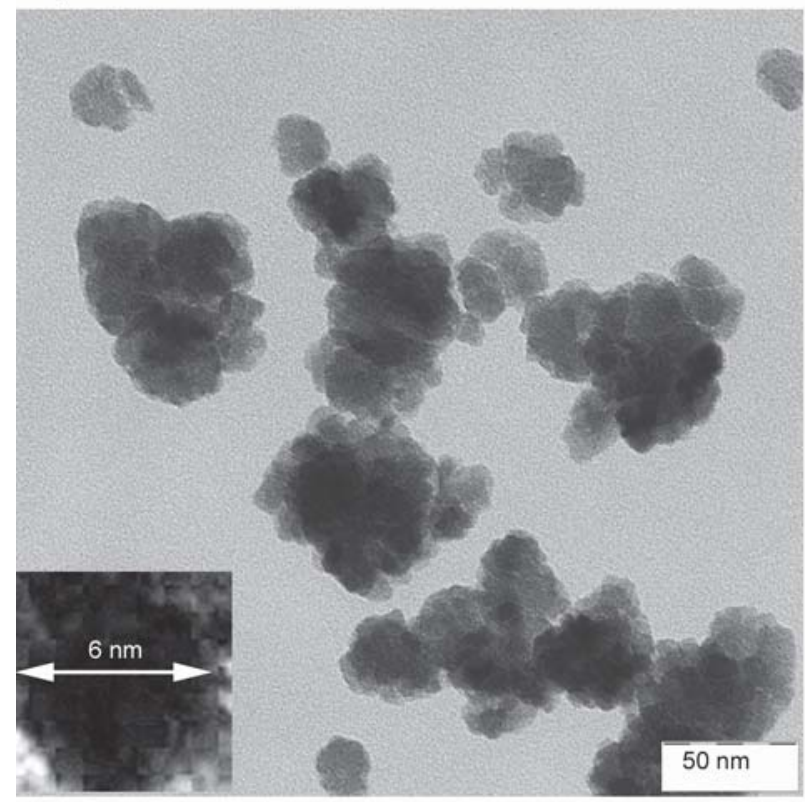

c)

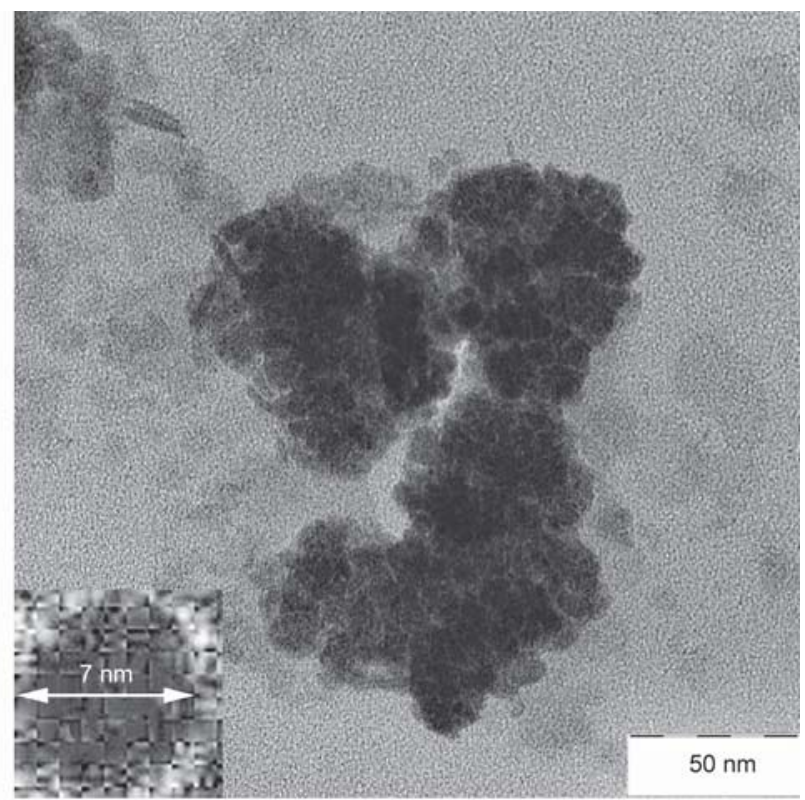

b)

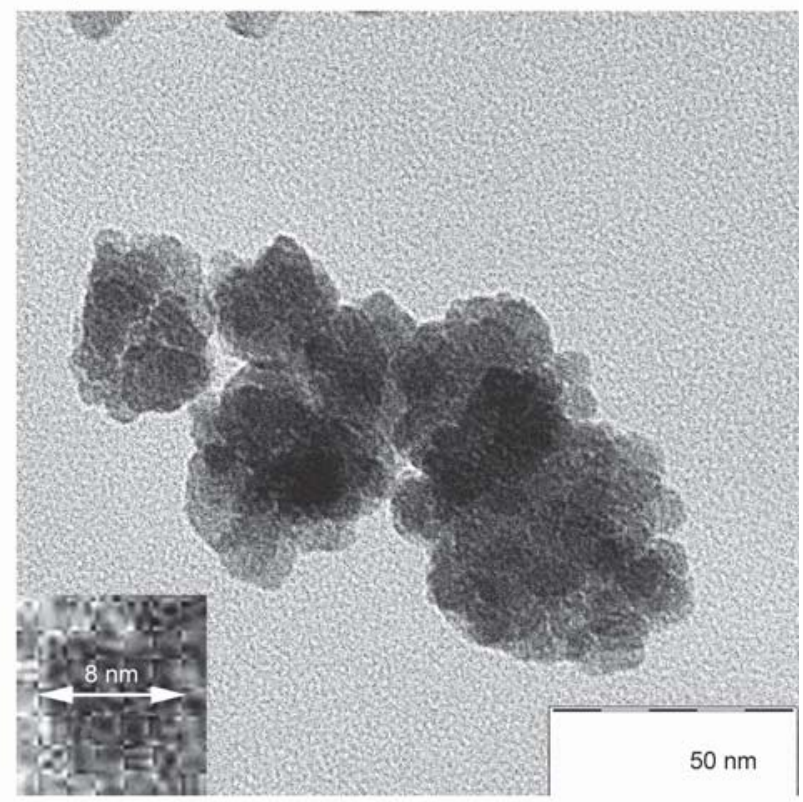

d)

Figure 1. TEM-images of the nanocomposites. Iron content: a) $3.4 \mathrm{wt} \%$ composite I, b) $4.8 \mathrm{wt} \%$ composite II, c) $10.5 \mathrm{wt} \%$ composite III and d) $18.1 \mathrm{wt} \%$ composite IV. Inserts in TEM-images demonstrate enlarged individual nanoparticles.

Microphotographs of the four obtained samples with different iron contents from Table 1 are presented in Figure 1.

Dark spherical particles are clearly visible on all the TEM images thus showing iron oxide in the four samples (in enlarged inserts). By the statistical processing of the TEM images, the size distribution of iron oxide nanoparticles was determined and found within 4 $20 \mathrm{~nm}$ range with a dominant diameter of $7 \pm 1 \mathrm{~nm}$ for all samples (Figure 2).

The typical electronogram of all nanocomposites (Figure 3) contains the same set of intense Bragg reflections indicating the identical crystal structure of the nanoparticles in the four nanocomposites.

XRD method allowed to look deeper inside the nanoparticle structure. The powder XRD patterns of the four nanocomposites are shown in Figure 4. Each diffraction pattern is a set of well-refined reflections at $2 \theta=30.25 ; 35.65 ; 42.25$ and $57.2 \AA$. According to a database of powder diffraction patterns provided by the International Center for Diffraction Data (ICDD) represented in Ref. [24] the above reflections correspond to the reflection planes (220), (311), (400), and (440) of crystalline iron oxides: magnetite 

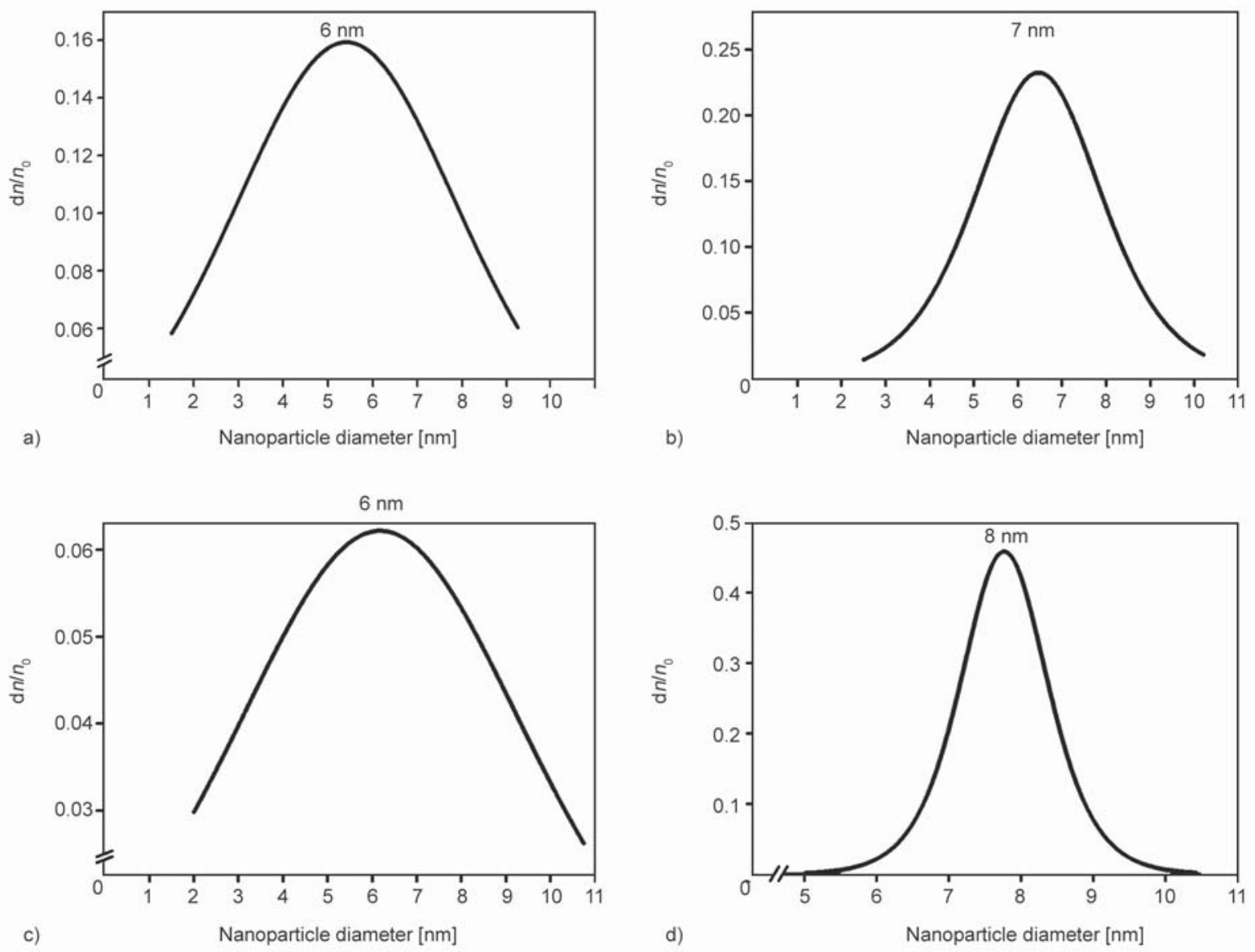

Figure 2. Distribution peaks of iron oxide nanoparticles by size. Iron content: a) $3.4 \mathrm{wt} \%$ composite I, b) $4.8 \mathrm{wt} \%$ composite II, c) $10.5 \mathrm{wt} \%$ composite III and d) $18.1 \mathrm{wt} \%$ composite IV.

$\mathrm{FeO}-\mathrm{Fe}_{2} \mathrm{O}_{3}$ and/or maghemite $\mathrm{Fe}_{2} \mathrm{O}_{3}$. By using the Scherrer equation [44] an average size of crystallites was estimated as $9 \pm 1 \mathrm{~nm}$ that was in excellent agreement with the TEM data.

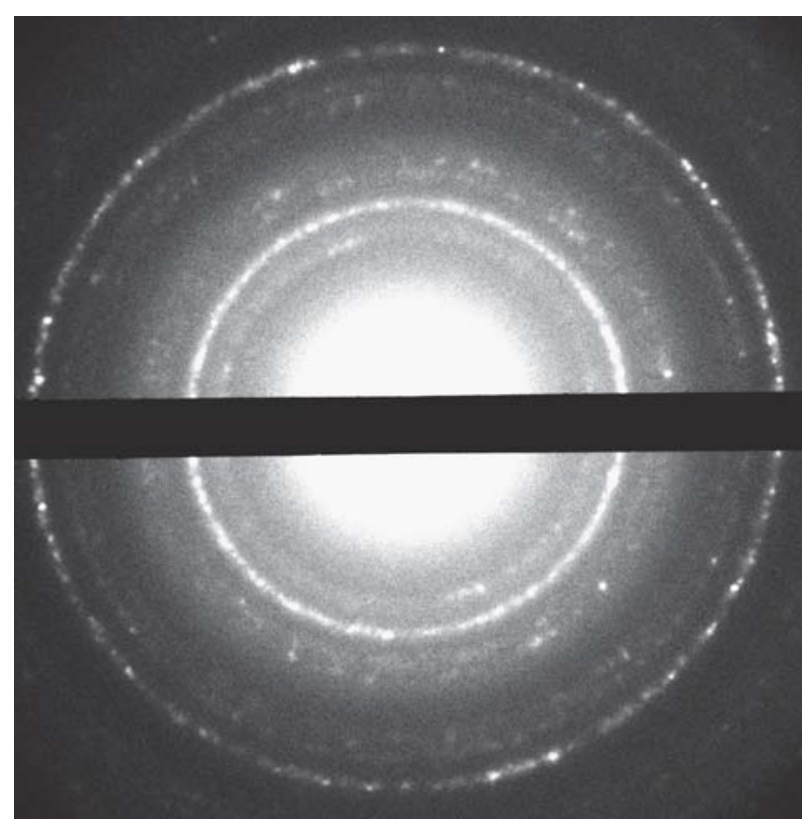

Figure 3. Electronogram of composite (III).
The interplanar distances, defining the crystalline structure of the oxide nanoparticles, were calculated by the Bragg formula (Table 2). For the reference samples of magnetite and maghemite, the corresponding values were taken from the ICDD database (represented in Ref. [24]). Comparison of the experimental and reference values indicated the crystalline lattice

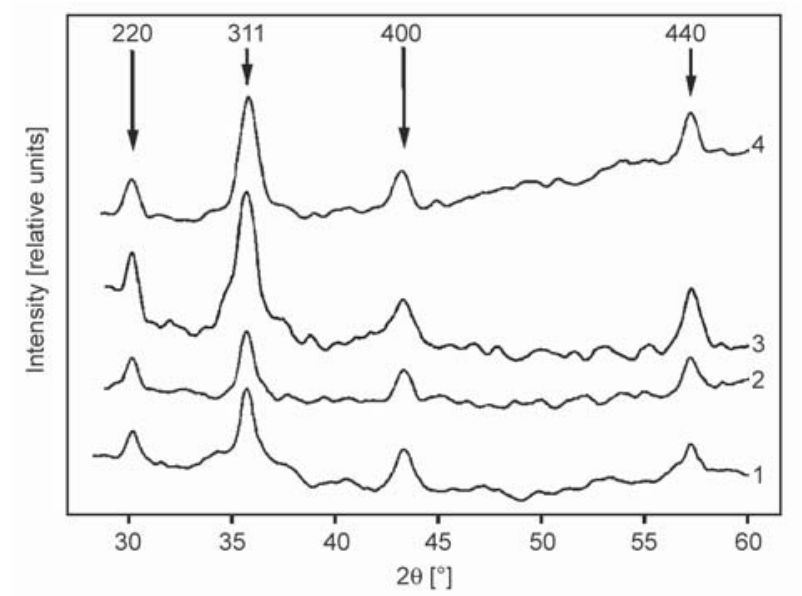

Figure 4. XRD patterns of composites I (1), II (2), III (3) and IV (4). 
Table 2. Interplanar distances calculated from for experimental X-ray data for the nanoparticles and extracted from ICDD database for iron oxides, $\gamma-\mathrm{Fe}_{2} \mathrm{O}_{3}$ and $\mathrm{Fe}_{3} \mathrm{O}_{4}$, as well as corresponding miller indices.

\begin{tabular}{|c|c|c|c|c|}
\hline No. & $h k l$ & $\begin{array}{l}d_{\text {exp }} \\
[\AA]]\end{array}$ & $\begin{array}{c}d_{\left(\gamma-\mathrm{Fe}_{2} \mathrm{O}_{3}\right)} \\
{[\tilde{\AA}]}\end{array}$ & $\begin{array}{c}d_{\left(\gamma-\mathrm{Fe}_{2} \mathrm{O}_{4}\right)} \\
{[\tilde{\AA}]}\end{array}$ \\
\hline 1 & 111 & $4.834 \pm 0.005$ & 4.822 & 4.852 \\
\hline 2 & 220 & $2.955 \pm 0.004$ & 2.953 & 2.967 \\
\hline 3 & 311 & $2.520 \pm 0.005$ & 2.517 & 2.532 \\
\hline 4 & 400 & $2.090 \pm 0.005$ & 2.088 & 2.099 \\
\hline 5 & 422 & $1.705 \pm 0.004$ & 1.704 & 1.714 \\
\hline 6 & 440 & $1.474 \pm 0.004$ & 1.475 & 1.484 \\
\hline
\end{tabular}

of maghemite for the synthesized nanoparticles with no other 'impurity' crystalline phases.

The chemical structure and dispersity of the nanoparticles was finally identified by means of Mossbauer spectroscopy. ${ }^{57} \mathrm{Fe}$ Mossbauer spectra of the composite IV with a maximum iron content of $18.1 \mathrm{wt} \%$ at 297 and $80 \mathrm{~K}$ are shown in Figure 5.

The spectrum obtained at $297 \mathrm{~K}$ (Figure 5a) illustrates a superparamagnetic behavior of the sample. The paramagnetic doublet with isomer shift $I_{\mathrm{s}}=$ $0.36 \mathrm{~mm} / \mathrm{s}$, quadrupole splitting $Q_{\mathrm{s}}=0.58 \mathrm{~mm} / \mathrm{s}$, magnetically split component with very large widths $\Gamma=1.94 \mathrm{~mm} / \mathrm{s}$ and average effective magnetic field of $368 \mathrm{kOe}$ were detected in the spectrum at $297 \mathrm{~K}$. At the same time no $\mathrm{Fe}_{3} \mathrm{O}_{4}$-nanoparticles characteristic signals (doublet with parameters $I_{\mathrm{s}}=0.4 \mathrm{~mm} / \mathrm{s}$ and quadrupole splitting $Q_{\mathrm{s}}=1.11 \mathrm{~mm} / \mathrm{s}$ ) were detected in this spectrum $[45,46]$. Thus, only $\gamma-\mathrm{Fe}_{2} \mathrm{O}_{3}$ nanoparticles were formed during the nanocomposite synthesis.

The estimation of nanoparticles sizes distribution was made by analyzing of the spectrum at $80 \mathrm{~K}$

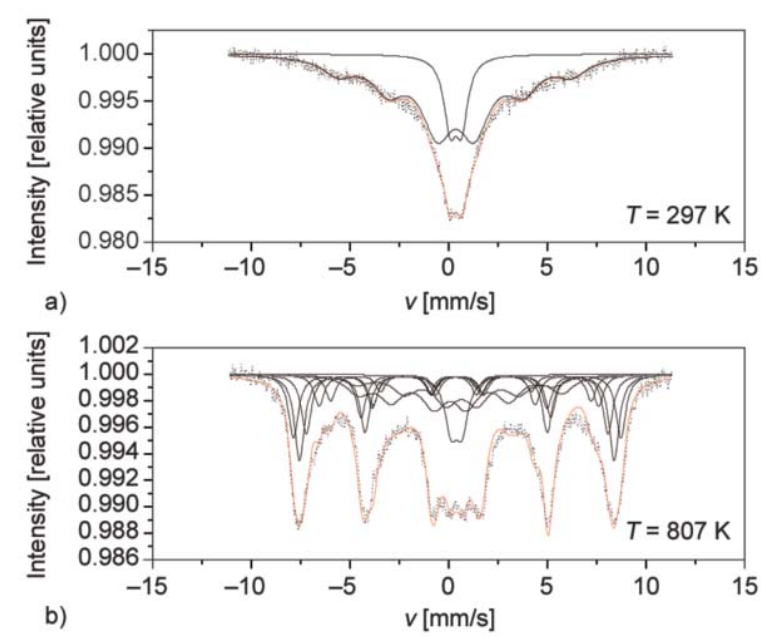

Figure 5. Mössbauer spectra of composite IV with $18.1 \mathrm{wt} \%$ iron content measured at 297 (a) and $80 \mathrm{~K}$ (b).
(Figure 5b). This spectrum contains paramagnetic doublet corresponding to $\gamma-\mathrm{Fe}_{2} \mathrm{O}_{3}$ nanoparticles with sizes $5-6 \mathrm{~nm}$, and relaxation components with $H_{\text {eff }}=$ 310-320 kOe. The set of well-split magnetic components with effective magnetic fields in the range 410-515 kOe appeared during the temperature decreasing down to $80 \mathrm{~K}$. Spectrum fitting and areas calculations of all those components allowed us to estimate $\gamma-\mathrm{Fe}_{2} \mathrm{O}_{3}$ nanoparticles size distribution: 5$6.5 \mathrm{~nm}-21 \%, 7-8 \mathrm{~nm}-45 \%, 8.5-9 \mathrm{~nm}-20 \%, 9.5-$ $10 \mathrm{~nm}-14 \%$. This distribution was in good agreement with distribution calculated from TEM images analysis.

FTIR technique was used to determine the nature of the interactions of between nanoparticles and polyanions.

The FTIR-spectra of the original alginate and alginate-maghemite composites with different maghemite contents are shown in Figure 6.

For the nanocomposites I-IV and original alginate no peaks were found in range $600-400 \mathrm{~cm}^{-1}$. No principal differences in spectra were recorded in range 4000-2000 $\mathrm{cm}^{-1}$. In the alginate spectrum (Figure 6 curve 1) the bands at $v=1600$ and $1420 \mathrm{~cm}^{-1}$ relate to the antisymmetric and symmetric stretching vibrations of carboxyl groups, respectively (Figure 6 curve 1). These groups are mainly in a deprotonated (charged) form [47, 48]. The band at $v=1730 \mathrm{~cm}^{-1}$ is associated with stretching vibrations of $\mathrm{C}=\mathrm{O}$ fragments in carboxyl groups; this band is due to intraand intermolecular hydrogen bond formation. The bands at $v=1220$ and $1025 \mathrm{~cm}^{-1}$ result from stretching vibrations of $\mathrm{C}-\mathrm{OH}$ fragments and $\mathrm{C}-\mathrm{O}-\mathrm{C}$ fragments in alginate macromolecule, respectively [49]. In FTIR spectra of the nanocomposites (Figure 6 curves 2-5), a gradual decrease in the intensity of the $v=1730 \mathrm{~cm}^{-1}$ peak is observed with an increase in the maghemite content. This indicates that the alginate carboxyl groups are not involved more in the H-bond formation most likely due to their interaction with the surface of maghemite nanoparticles. A progressive decrease in the intensities of the $v=1220$ and $=1025 \mathrm{~cm}^{-1}$ peaks apparently means $\mathrm{Fe}^{3+}$ maghemite ions coordinate the hydroxyl and ether groups thus making them 'invisible' in the IR spectra. These results allow the conclusion about incorporation of maghemite nanoparticles into the alginate matrix via formation of electrostatic and coordination contacts between the surface $\mathrm{Fe}^{3+}$ maghemite ions and functional alginate groups. 


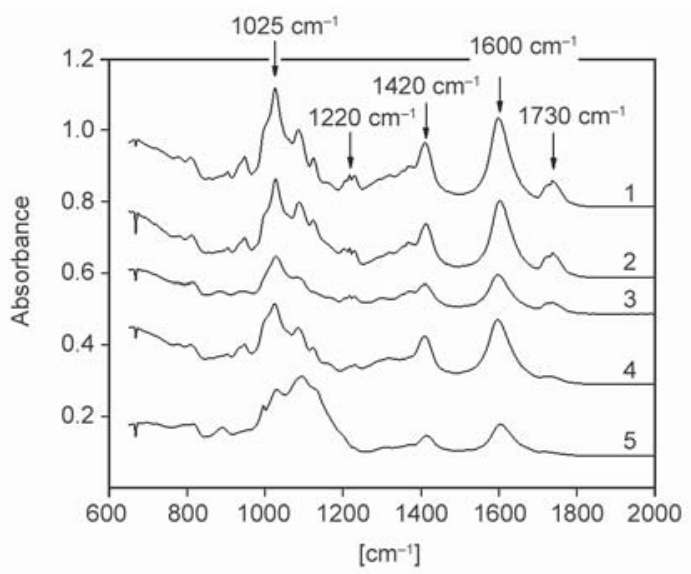

Figure 6. FTIR- spectra of alginate (1), composite I (2), composite II (3), composite III (4) and composite IV (5).

The specific magnetizations of the nanocomposites vs. applied magnetic field are represented in Figure 7. The profiles of the magnetization curves are evidence of ferromagnetic properties of the nanocomposites. From these curves, the magnetostatic characteristics: saturation magnetization $\left(I_{\mathrm{s}}\right)$, residual magnetization $\left(I_{\mathrm{r}}\right)$, coercive force $\left(H_{\mathrm{c}}\right)$ and squareness coefficient $\left(I_{\mathrm{r}} / I_{\mathrm{S}}\right)$, were calculated and summarized in Table 3.

The data of Table 3 show that Is increases from 1.8 to $23.1 \mathrm{emu} / \mathrm{g}$ with elevating the content of maghemite in the nanocomposite. In the same series of nanocomposites the $I_{\mathrm{r}}$ value varied from 0.21 up to $2.56 \mathrm{emu} / \mathrm{g}$. These results show the relationship between the content of maghemite domains and the magnetic characteristics of nanocomposites.

At the same time, both $H_{\mathrm{c}}$ and $I_{\mathrm{s}} / I_{\mathrm{r}}$ do not change with the elevating the maghemite content. The $H_{\mathrm{c}}$ value lies within a $51.4 \pm 0.5$ Oe range while $I_{\mathrm{r}} / I_{\mathrm{S}}$ within a $0.112 \pm 0.004$ range. The latter is particularly

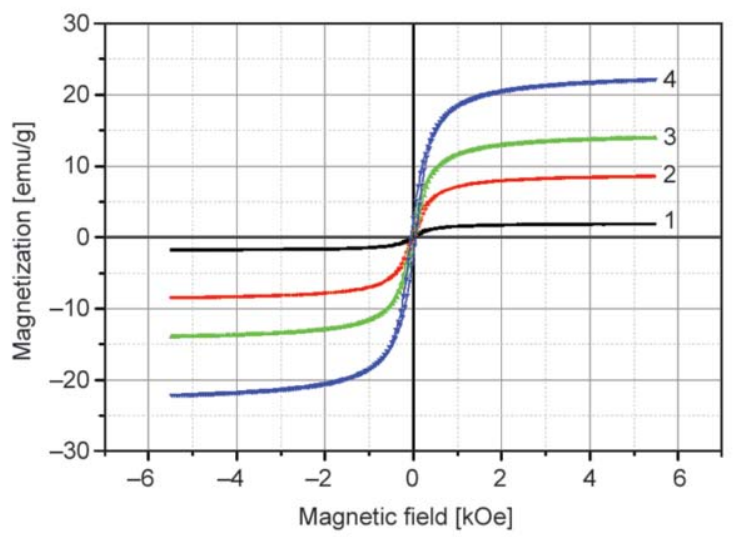

Figure 7. Magnetization curves of composites I (1), II (2), III (3) and IV (4) at $300 \mathrm{~K}$.
Table 3. Magnetic characteristics of alginate-maghemite nanocomposites.

\begin{tabular}{|l|c|c|c|c|}
\hline Composites & $\begin{array}{c}\boldsymbol{I}_{\mathbf{s}} \\
{[\mathbf{e m u} / \mathbf{g}]}\end{array}$ & $\begin{array}{c}\boldsymbol{H}_{\mathbf{c}} \\
{[\mathbf{O e}]}\end{array}$ & $\begin{array}{c}\boldsymbol{I}_{\mathbf{r}} \\
{[\mathbf{e m u} / \mathbf{g}]}\end{array}$ & $\boldsymbol{I}_{\mathbf{r}} / \boldsymbol{I}_{\mathbf{s}}$ \\
\hline I & 1.8 & 51.9 & 0.21 & 0.116 \\
\hline II & 8.8 & 51.0 & 0.95 & 0.108 \\
\hline III & 14.4 & 51.4 & 1.62 & 0.112 \\
\hline IV & 23.1 & 51.0 & 2.56 & 0.111 \\
\hline
\end{tabular}

noteworthy since it indicates that the nanocomposites are soft magnetic materials.

The operational magnetic characteristics of the nanocomposites, saturation magnetization and residual magnetization, are effectively controlled by the component ratio.

In order to demonstrate magnetic properties of the nanocomposites, the following experiment was performed. A uniformly colored composite III aqueous solution (Figure 8a) was placed over the magnet that caused the nanocomposite particles to move down towards the magnet thus forming a dark disk on the bottom of the test-tube (Figure 8b). A further transfer of the magnet to the top of the test-tube caused the particles to move upwards as shown by a dark thread in Figure 8c. It should be noted that in absence of magnetic field this $1 \mathrm{wt} \%$ water solution has demonstrated fine stability (no precipitation or phase separation occurred) for at least 1 month.

\section{Conclusions}

A one-step procedure was designed for the preparation of biocompatible nanocomposites from $\gamma-\mathrm{Fe}_{2} \mathrm{O}_{3}$ maghemite nanoparticles and a natural polysaccharide, water-soluble sodium/calcium alginate. Following the procedure, a series of magneto-sensitive nanocomposites with a controlled content of maghemite was synthesized and characterized. An average diameter of the maghemite nanoparticles was found to be of $7 \pm 1 \mathrm{~nm}$ according to transmission electron microscopy. As shown by FTIR spectroscopy, the nanoparticles complex with the polymer matrix via electrostatic and coordination interactions; the complexation restricts the nanoparticle growth and stabilizes them against aggregation. The nanocomposites were shown to be soft magnetic nanomaterials which form stable aqueous dispersions sensitive to an external magnetic field. The biocompartible maghemite-alginate nanocomposites seem to be promising for encapsulation and delivery of biologically active compounds. 


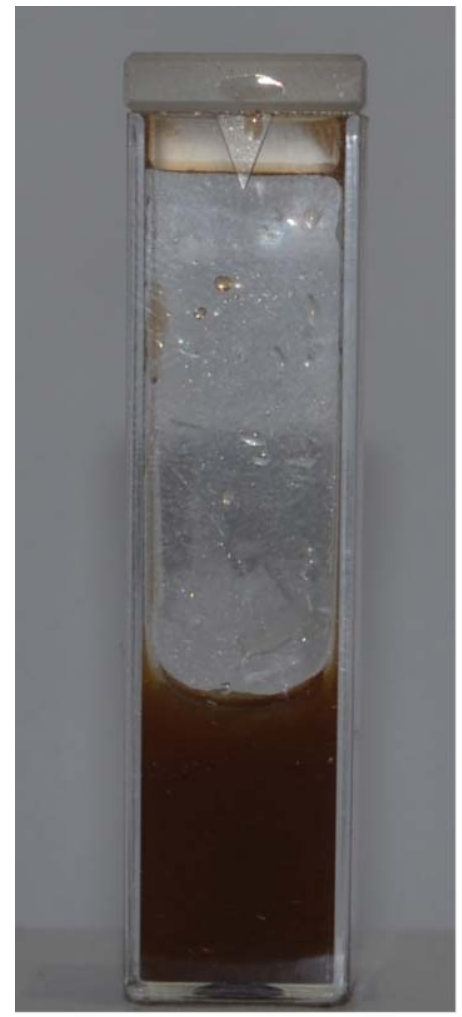

a)

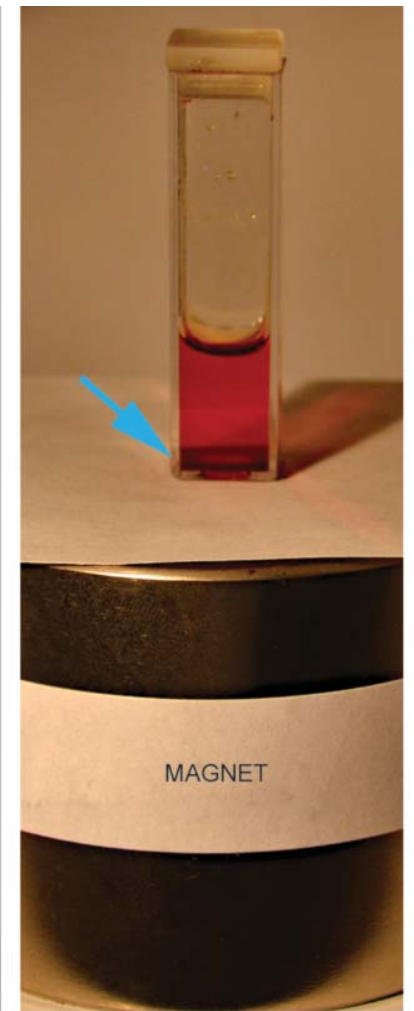

b)

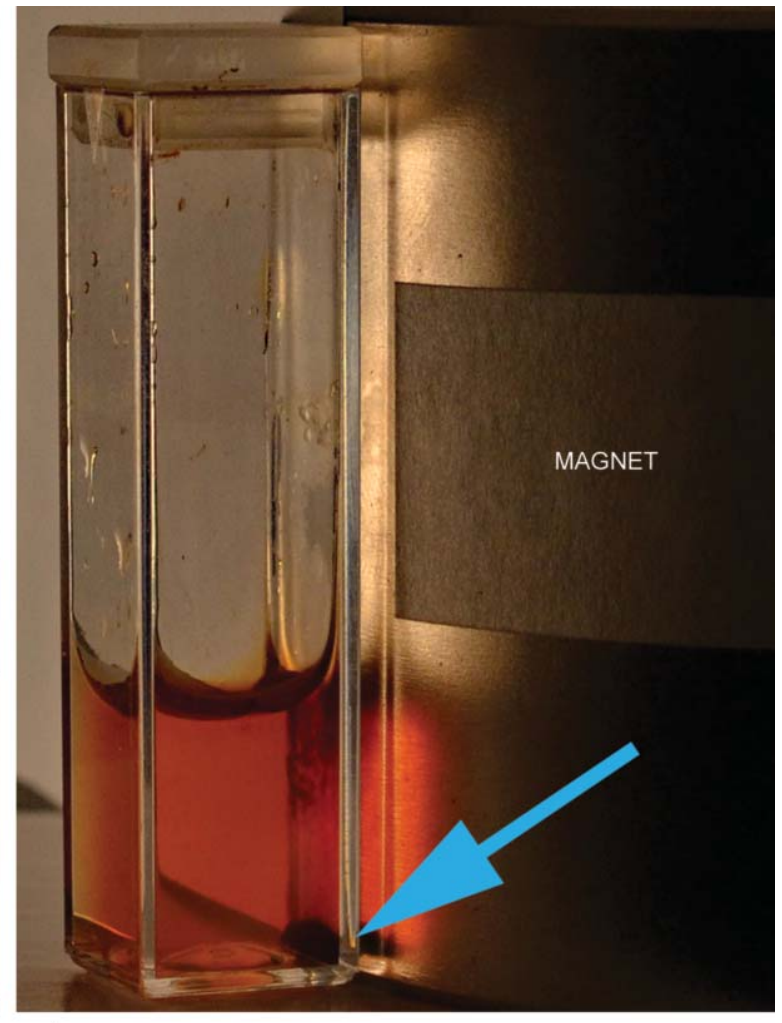

c)

Figure 8. Effect of magnetic field on the behaviour of $1 \mathrm{wt} \%$ composite III aqueous solution. Arrow indicates magnet-induced accumulation of nanocomposite. a) sample without magnet, b) sample with magnet at the bottom, c) sample with magnet on the left

\section{Acknowledgements}

This work was supported in part by Russian Foundation for Basic Research (project 17-03-00433)

\section{References}

[1] Tietze R., Zaloga J., Unterweger H., Lyer S., Friedrich R. P., Janko C., Pöttler M., Dürr S., Alexiou C.: Magnetic nanoparticle-based drug delivery for cancer therapy. Biochemical And Biophysical Research Communications, 468, 463-470 (2015). https://doi.org/10.1016/j.bbrc.2015.08.022

[2] Veiseh O., Gunn J. W., Zhang M.: Design and fabrication of magnetic nanoparticles for targeted drug delivery and imaging. Advanced Drug Delivery Reviews, 62, 284-304 (2010).

https://doi.org/10.1016/j.addr.2009.11.002

[3] Mody V. V., Cox A., Shah S., Singh A., Bevins W., Parihar H.: Magnetic nanoparticle drug delivery systems for targeting tumor. Applied Nanoscience, 4, 385-392 (2014).

https://doi.org/10.1007/s13204-013-0216-y

[4] Munaweera I., Shi Y., Koneru B., Saez R., Aliev A., Di Pasqua A. J., Balkus-Jr K. J.: Chemoradiotherapeutic magnetic nanoparticles for targeted treatment of nonsmall cell lung cancer. Molecular Pharmaceutics, 12, 3588-3596 (2015).

https://doi.org/10.1021/acs.molpharmaceut.5b00304
[5] Bañobre-López M., Teijeiro A., Rivas J.: Magnetic nanoparticle-based hyperthermia for cancer treatment. Reports of Practical Oncology and Radiotherapy, 18, 397-400 (2013).

https://doi.org/10.1016/j.rpor.2013.09.011

[6] Kumar C. S. S. R., Mohammad F.: Magnetic nanomaterials for hyperthermia-based therapy and controlled drug delivery. Advanced Drug Delivery Reviews, 63, 789-808 (2011).

https://doi.org/10.1016/j.addr.2011.03.008

[7] Vegerhof A., Motei M., Rudinzky A., Malka D., Popovtzer R., Zalevsky Z.: Thermal therapy with magnetic nanoparticles for cell destruction. Biomedical Optics Express, 7, 4581-4594 (2016). https://doi.org/10.1364/BOE.7.004581

[8] Shetake N. G., Balla M. M. S., Kumar A., Pandey B. N.: Magnetic hyperthermia therapy: An emerging modality of cancer treatment in combination with radiotherapy. Journal of Radiation and Cancer Research, 7, 13-17 (2016).

https://doi.org/10.4103/0973-0168.184606

[9] Coïsson M., Barrera G., Celegato F., Martino L., Vinai F., Martino P., Ferraro G., Tiberto P.: Specific absorption rate determination of magnetic nanoparticles through hyperthermia measurements in non-adiabatic conditions. Journal of Magnetism and Magnetic Materials, 415, 2-7 (2016).

https://doi.org/10.1016/j.jmmm.2015.11.044 
[10] Granata C., Russo R., Esposito E., Vettoliere A., Russo M., Musinu A., Peddis D., Fiorani D.: Magnetic properties of iron oxide nanoparticles investigated by nanoSQUIDs. The European Physical Journal B, 86, 272 276 (2013).

https://doi.org/10.1140/epjb/e2013-40051-2

[11] Ali A., Zafar H., Zia M., ul Haq I., Phull A. R., Ali J. S., Hussain A.: Synthesis, characterization, applications, and challenges of iron oxide nanoparticles. Nanotechnology, Science and Applications, 9, 49-67 (2016). https://doi.org/10.2147/NSA.S99986

[12] Schwaminger S. P., Bauer D., Fraga-García P., Wagner F. E., Berensmeie S.: Oxidation of magnetite nanoparticles: Impact on surface and crystal properties. CrystEngComm, 19, 246-255 (2017).

https://doi.org/10.1039/C6CE02421A

[13] Karimi Z., Karimi L., Shokrollahi H.: Nano-magnetic particles used in biomedicine: Core and coating materials. Materials Science and Engineering: C, 33, 24652475 (2013).

https://doi.org/10.1016/j.msec.2013.01.045

[14] Xiao L., Li J., Brougham D. F., Fox E. K., Feliu N., Bushmelev A., Schmidt A., Mertens N., Kiessling F., Valldor M., Fadeel B., Mathur S.: Water-soluble superparamagnetic magnetite nanoparticles with biocompatible coating for enhanced magnetic resonance imaging. ACS Nano, 5, 6315-6324 (2011).

https://doi.org/10.1021/nn201348s

[15] Wu W., Wu Z., Yu T., Jiang C., Kim W-S.: Recent progress on magnetic iron oxide nanoparticles: Synthesis, surface functional strategies and biomedical applications. Science And Technology of Advanced Materials, 16, 023501/1-023501/43 (2015)

https://doi.org/10.1088/1468-6996/16/2/023501

[16] Hergt R., Hiergeist R., Hilger I., Kaiser W. A., Lapatnikov Y., Margel S., Richter U.: Maghemite nanoparticles with very high AC-losses for application in RF-magnetic hyperthermia. Journal of Magnetism and Magnetic Materials, 270, 345-357 (2004).

https://doi.org/10.1016/j.jmmm.2003.09.001

[17] Gorin D. A., Portnov S. A., Inozemtseva O. A., Luklinska Z., Yashchenok A. M., Pavlov A. M., Skirtach A. G., Möhwald H., Sukhorukov G. B.: Magnetic/gold nanoparticle functionalized biocompatible microcapsules with sensitivity to laser irradiation. Physical Chemistry Chemical Physics, 10, 6899-6905 (2008).

https://doi.org/10.1039/B809696A

[18] Jia Y., Yuan M., Yuan H., Huang X., Sui X., Cui X., Tang F., Peng J., Chen J., Lu S., Xu W., Zhang L., Guo Q.: $C o$-encapsulation of magnetic $\mathrm{Fe}_{3} \mathrm{O}_{4}$ nanoparticles and doxorubicin into biodegradable PLGA nanocarriers for intratumoral drug delivery. International Journal of Nanomedicine, 7, 1697-1708 (2012).

https://doi.org/10.2147/IJN.S28629
[19] Gaharwar A. K., Wong J. E., Müller-Schulte D., Bahadur D., Richtering W.: Magnetic nanoparticles encapsulated within a thermoresponsive polymer. Journal of Nanoscience and Nanotechnology, 9, 5355-5361 (2009).

[20] Jokerst J. V., Lobovkina T., Zare R. N., Gambhir S. S.: Nanoparticle PEGylation for imaging and therapy. Nanomedicine, 6, 715-728 (2011).

https://doi.org/10.2217/nnm.11.19

[21] Lemarchand C., Gref R., Couvreur P.: Polysaccharidedecorated nanoparticles. European Journal of Pharmaceutics and Biopharmaceutics, 58, 327-341 (2004). https://doi.org/10.1016/j.ejpb.2004.02.016

[22] Ahmed T. A., Aljaeid B. M.: Preparation, characterization, and potential application of chitosan, chitosan derivatives, and chitosan metal nanoparticles in pharmaceutical drug delivery. Drug Design, Development and Therapy, 10, 483-507 (2016). https://doi.org/10.2147/DDDT.S99651

[23] Kang D. H., Jung H-S., Ahn N., Yang S. M., Seo S., Suh K-Y., Chang P-S., Jeon N. L., Kim J., Kim K.: Janus-compartmental alginate microbeads having polydiacetylene liposomes and magnetic nanoparticles for visual lead(II) detection. ACS Applied Materials and Interfaces, 6, 10631-10637 (2014).

https://doi.org/10.1021/am502319m

[24] Luna-Martínez J. F., Reyes-Melo E., González-González V., Guerrero-Salazar C., Torres-Castro A., SepúlvedaGuzmán S.: Synthesis and characterization of a magnetic hybrid material consisting of iron oxide in a carboxymethyl cellulose matrix. Journal of Applied Polymer Science, 127, 2325-2331 (2013).

https://doi.org/10.1002/app.37892

[25] Rioux L-E., Turgeon S. L., Beaulieu M.: Characterization of polysaccharides extracted from brown seaweeds. Carbohydrate Polymers, 69, 530-537 (2007). https://doi.org/10.1016/j.carbpol.2007.01.009

[26] Pawar S. N., Edgar K. J.: Alginate derivatization: A review of chemistry, properties and applications. Biomaterials, 33, 3279-3305 (2012). https://doi.org/10.1016/j.biomaterials.2012.01.007

[27] Patel N., Lalwani D., Gollmer S., Injeti E., Sari Y., Nesamony J.: Development and evaluation of a calcium alginate based oral ceftriaxone sodium formulation. Progress in Biomaterials, 5, 117-133 (2016). https://doi.org/10.1007/s40204-016-0051-9

[28] Tønnesen H. H., Karlsen J.: Alginate in drug delivery systems. Drug Development and Industrial Pharmacy, 28, 621-630 (2002). https://doi.org/10.1081/DDC-120003853

[29] Fujihara V., Nagumo N.: An influence of the structure of alginate on the chemotactic activity of macrophages and the antitumor activity. Carbohydrate Research, 243, 211-216 (1993). https://doi.org/10.1016/0008-6215(93)84094-M 
[30] Otterlei M., Ostgaard K., Skjåk-Braek G., Smidsrød O., Soon-Shiong P., Espevik T.: Induction of cytokine production from human monocytes stimulated with alginate. Journal of Immunotherapy, 10, 286-291 (1991).

[31] Tusi S. K., Khalaj L., Ashabi G., Kiaei M., Khodagholi F.: Alginate oligosaccharide protects against endoplasmic reticulum- and mitochondrial-mediated apoptotic cell death and oxidative stress. Biomaterials, 32, 54385458 (2011).

https://doi.org/10.1016/j.biomaterials.2011.04.024

[32] Choi I., Jo G., Kim S., Jung C. W., Kim Y., Shin K.: Stimulation of various functions in murine peritoneal macrophages by glucans produced by glucosyltransferases from Streptococcus mutans. Bioscience, Biotechnology, and Biochemistry, 69, 1693-1699 (2005).

https://doi.org/10.1271/bbb.69.1693

[33] Eral H. B., López-Mejías V., O’Mahony M., Trout B. L., Myerson A. S., Doyle P. S.: Biocompatible alginate microgel particles as heteronucleants and encapsulating vehicles for hydrophilic and hydrophobic drugs. Crystal Growth and Design, 14, 2073-2082 (2014).

https://doi.org/10.1021/cg500250e

[34] Belščak-Cvitanović A., Komes D., Karlović S., Djaković S., Spoljarić I., Mršić G., Ježek D.: Improving the controlled delivery formulations of caffeine in alginate hydrogel beads combined with pectin, carrageenan, chitosan and psyllium. Food Chemistry, 167, 378-386 (2015).

https://doi.org/10.1016/j.foodchem.2014.07.011

[35] Laurienzo P.: Marine polysaccharides in pharmaceutical applications: An overview. Marine Drugs, 8, 2435 2465 (2010).

https://doi.org/10.3390/md8092435

[36] Laurent S., Forge D., Port M., Roch A., Robic C., Van der Elst L., Muller R. N.: Magnetic iron oxide nanoparticles: Synthesis, stabilization, vectorization, physicochemical characterizations, and biological applications. Chemical Reviews, 108, 2064-2110 (2008).

https://doi.org/10.1021/cr068445e

[37] Ma H-L., Qi X-R., Maitani Y., Nagai T.: Preparation and characterization of superparamagnetic iron oxide nanoparticles stabilized by alginate. International Journal of Pharmaceutics, 333, 177-186 (2007).

https://doi.org/10.1016/j.ijpharm.2006.10.006

[38] Ma H. L., Xu Y. F., Qi X. R., Maitani Y., Nagai T.: Superparamagnetic iron oxide nanoparticles stabilized by alginate: Pharmacokinetics, tissue distribution, and applications in detecting liver cancers. International Journal of Pharmaceutics, 354, 217-226 (2008)

https://doi.org/10.1016/j.ijpharm.2007.11.036

[39] Mohammadi A., Daemi H., Barikani M.: Fast removal of malachite green dye using novel superparamagnetic sodium alginate-coated $\mathrm{Fe}_{3} \mathrm{O}_{4}$ nanoparticles. International Journal of Biological Macromolecules, 69, 447455 (2014).

https://doi.org/10.1016/j.ijbiomac.2014.05.042
[40] Lakouraj M. M., Mojerlou F., Zare E. N.: Nanogel and superparamagnetic nanocomposite based on sodium alginate for sorption of heavy metal ions. Carbohydrate Polymers, 106, 34-41 (2014).

https://doi.org/10.1016/j.carbpol.2014.01.092

[41] Zare E. N., Lakouraj M. M., Mohseni M., Motahari A.: Multilayered electromagnetic bionanocomposite based on alginic acid: Characterization and biological activities. Carbohydrate Polymers, 130, 372-380 (2015). https://doi.org/10.1016/j.carbpol.2015.05.020

[42] Bar-Shir A., Avram L., Yariv-Shoushan S., Anaby D., Cohen S., Segev-Amzaleg N., Frenkel D., Sadan O., Offen D., Cohen Y.: Alginate-coated magnetic nanoparticles for noninvasive MRI of extracellular calcium. NMR in Biomedicine, 27, 774-783 (2014).

https://doi.org/10.1002/nbm.3117

[43] Topchieva I. N., Spiridonov V. V., Zakharov A. N., Afanasov M. I., Mironov A. V., Perov N. S., Semisalova A. S.: Room temperature one-pot preparation of magnetically ordered iron(III) oxide from aerated aqueous solutions of FeII salts in the presence of 2-hydroxypropyl$\beta$-cyclodextrin. Mendeleev Communications, 25, 145147 (2015).

https://doi.org/10.1016/j.mencom.2015.03.024

[44] Braga T. P., Vasconcelos I. F., Sasaki J. M., Fabris J. D., de Oliveira D. Q. L., Valentini A.: Magnetic composites based on hybrid spheres of aluminum oxide and superparamagnetic nanoparticles of iron oxides. Journal of Magnetism and Magnetic Materials, 322, 633-637 (2010) https://doi.org/10.1016/j.jmmm.2009.10.028

[45] Oshtrakh M. I., Ushakov M. V., Šepelák V., Semionkin V. A., Morais P. C.: Study of iron oxide nanoparticles using Mössbauer spectroscopy with a high velocity resolution. Spectrochimica Acta Part A: Molecular and Biomolecular Spectroscopy, 152, 666-679 (2016) https://doi.org/10.1016/j.saa.2015.06.017

[46] Mørup S.: Mössbauer effect studies of microcrystalline materials. in 'Mössbauer spectroscopy applied to inorganic chemistry, Vol 2' (eds.: Long G. J) Plenum Press, New York, 89-123 (1984).

[47] Gazori T., Khoshayand M. R., Azizi E., Yazdizade P., Nomani A., Haririan I.: Evaluation of alginate/chitosan nanoparticles as antisense delivery vector: Formulation, optimization and in vitro characterization. Carbohydrate Polymers, 77, 599-606 (2009).

https://doi.org/10.1016/j.carbpol.2009.02.019

[48] Spiridonov V. V., Panova I. G., Makarova L. A., Afanasov M. I., Zezin S. B., Sybachin A. V., Yaroslavov A. A.: The one-step synthesis of polymer-based magnetic $\gamma-\mathrm{Fe}_{2} \mathrm{O}_{3}$ /carboxymethyl cellulose nanocomposites. Carbohydrate Polymers 177, 269-274 (2017)

https://doi.org/10.1016/j.carbpol.2017.08.126

[49] Daemi H., Barikani M.: Synthesis and characterization of calcium alginate nanoparticles, sodium homopolymannuronate salt and its calcium nanoparticles. Scientia Iranica, 19, 2023-2028 (2012). https://doi.org/10.1016/j.scient.2012.10.005 